\title{
Cell Cycle Related Differentiation of Bone Marrow Cells into Lung Cells
}

Mark S. Dooner ${ }^{1} *$, Jason Aliotta ${ }^{1}$, Jeffery Pimentel ${ }^{1}$, Gerri J. Dooner ${ }^{1}$, Mehrdad Abedi $^{1}$, Gerald Colvin $^{1}$, Qin Liu ${ }^{2}$, Heinz-Ulli Weier ${ }^{3}$, Peter J. Quesenberry ${ }^{1}$

Center for Stem Cell Biology, Research Department, Roger Williams Medical Center, Providence, R.I. 02908 U.S.A ${ }^{1}$.

University of Massachusetts Medical Center, Worcester, $\mathrm{MA}^{2}$

Life Sciences Division, Lawrence Berkeley National Laboratory, Berkeley, CA $94720{ }^{3}$

* Equal contributions

Corresponding Author: Mark Dooner

Roger Williams Medical Center

825 Chalkstone Ave, Providence, R.I. 02908

Phone- 401-456-5771

Fax- 401-456-5759

mdooner@rwmc.org 


\begin{abstract}
.
Green-fluorescent protein (GFP) labeled marrow cells transplanted into lethally irradiated mice can be detected in the lungs of transplanted mice and have been shown to express lung specific proteins while lacking the expression of hematopoietic markers. We have studied marrow cells induced to transit cell cycle by exposure to IL-3, IL-6, IL-11 and steel factor at different times of culture corresponding to different phases of cell cycle. We have found that marrow cells at the G1/S interface have a 3-fold increase in cells which assume a lung phenotype and that this increase is no longer seen in late S/G2. These cells have been characterized as GFP ${ }^{+} \mathrm{CD}^{-} 5^{-}$and $\mathrm{GFP}^{+}$cytokeratin ${ }^{+}$. Thus marrow cells with the capacity to convert into cells with a lung phenotype after transplantation show a reversible increase with cytokine induced cell cycle transit.

Previous studies have shown the phenotype of bone marrow stem cells fluctuates reversibly as these cells traverse cell cycle, leading to a continuum model of stem cell regulation. The present studies indicate that marrow stem cell production of nonhematopoietic cells also fluctuates on a continuum.
\end{abstract}


Introduction

Marrow stem /progenitor cell regulation has classically been felt to be on a hierarchical basis (1$3)$. Recent studies on the ability of marrow cells to produce both hematopoietic and nonhematopoietic cells in a variety of tissues, including skeletal muscle (4-7), liver (8-10), and lung (11-13) have raised controversial issues as to the inherent plasticity of adult marrow stem cells and challenged basic hierarchical models.

In many respects the marrow stem cell has been defined by its ability to home to marrow of irradiated or nonirradiated mice. Transplanted cells distribute in the vasculature of the mouse and it has been estimated that from 6 to $9 \%$ of infused stem cells end up residing in the marrow $(14,15)$ These homing events are then followed by stable marrow engraftment. Habibian et al (16 ) demonstrated that marrow cells stimulated in vitro with cytokines and driven through cell cycle showed a reversible defect in engraftment at 26-32 hours of in vitro culture which then returned to baseline input values at latter time points in culture. The cells showing an engraftment defect were in late S/early G2 while normal engraftment was seen in G1. Cerny et al (14) showed that a defect in homing probably was responsible for the observed cell cycle related defect in engraftment.

In studies focused on the hematopoietic system, we have found that the phenotype of primitive marrow stem cells fluctuates reversibly with cell cycle transit (17-21). As noted above, the engraftment capacity of stem cells reversibly changes as stem cells transit cycle $(16,22)$ and there are also alterations in homing (14). Adhesion protein expression $(23,24)$, global gene expression (22), and progenitor numbers (25) are also tied to different phases of cell cycle. Progenitor cell levels and engraftment capacity showed an inverse relationship (25). In addition, the capacity of stem cells to differentiate into megakaryocytes and granulocytes was tied closely to specific points in cell cycle and was also reversible (26). These observations might be of less biologic significance if the marrow stem cell was a quiescent non-cycling cell, as has been dogma over the years. However, this is not the case. Definitive studies by Bradford and colleagues (27), confirmed by others $(28,29)$, showed that a quiescent primitive marrow stem cell population, the lineage-negative, rhodamine ${ }^{\text {low }}$ Hoechst ${ }^{\text {low }}(\mathrm{LRH})$ cell, is either continually or intermittently in cell cycle. Bradford et al (27) provided BrdU in the drinking water of mice, subsequently sacrificed the mice, and determined BrdU labeling of $\mathrm{LRH}$. They found that there was $60 \%$ labeling by 4 weeks. Work by Cheshire et al (28), using a different mouse strain and stem cell separation, confirmed this work, but showed more rapid labeling kinetics. This is consistent with the work of Fleming et al (30) showing that $18-22 \%$ of Thy1.1lo Lin $/ /$ oSca- $1^{+}$marrow cells have over 2 N DNA content. These observations indicate that stem cells continuously alter phenotype as they progress through cell cycle and that these alterations are reversible. Stem cells are in cycle, so presumably the in vivo phenotype of the marrow stem cell is constantly changing over time. This has led to a continuum model of stem cell regulation in which a change in phenotype is tied to cycle related changes in transcription factor access to different promoter regions (17-21). This is also consistent with the phase-space model of Kirkland (31) and the stochastic model of Roeder and colleagues (32).

Marrow cell production of lung cells has also been reported by many groups, although the quantitative extent of such events has varied widely. We have reported on the production of lung cells by marrow cells in irradiated mice (13) and demonstrated that these results were not due to false reading of auto fluorescence or due to misinterpretation of sections with overlapping cells. The latter was addressed using deconvolution fluorescent microscopy. In essence, we have engrafted green-fluorescent protein (GFP) transgenic marrow into lethally irradiated C57BL/6 mice, and shown that 3.4 to $5.43 \%$ of cells within the lung are GFP ${ }^{+}$CD45, which we have defined as being donor marrow derived lung cells. Sixty percent of these cells are also cytokeratin positive suggesting that these cells are donor derived pulmonary epithelial cells. We have also shown that administration of G-CSF with stem cell mobilization increases the number of donor-derived GFP ${ }^{+} \mathrm{CD} 45^{-}$cells to $7.48 \%$. These data, along with reports by others (11-13), 
indicate that bone marrow cells have the capacity in vivo to produce nonhematopoietic lung cells with epithelial markers. In the present study, we have addressed whether this converting capacity of marrow into lung would vary with cell cycle status. We have addressed both early homing to lung and long term engraftment fates of marrow cells in lung.

\section{Results:}

\section{Homing and Persistence}

We assessed homing of freshly isolated and cultured (IL-3, IL-6, IL-11 and steel factor) lin ${ }^{-S c a-1}{ }^{+}$ marrow cells to lung at 3 hours, 7 , and 14 days. In these studies, CFSE or GFP ${ }^{+}$cells were followed and fluorescent events per tissue section or marrow cell population recorded. Host recipient mice were either untreated or exposed to 1000 cGy whole body irradiation. In nonirradiated mice, homing to the lung was significantly increased at 24 hours of culture $(p<0.05)$ (Fig. $1 \mathrm{C} \& D$ ), which, corresponds to G1/S interface (Fig. 1A). It had returned to baseline by 40 hours (Fig. 1D). The elevation of homed Lin Sca- $1^{+}$cells at 24 hours of culture was confirmed in two separate experiments in which lung cells were analyzed by flow cytometry. There was a mean 1833\% increase at 24 hours. Bone marrow homing at 18 and 24 hours is decreased (Fig. 1B). Homing in liver, spleen and heart did not show dramatic increases at 24 hours of culture (Fig $1 \mathrm{C})$

We evaluated homing and persistence of GFP ${ }^{+}$Lin Sca- $1^{+}$cells in lung at 3 hours 7 days and 14 days after cell infusion into irradiated (1000 cGy) mice(Fig 2 A-C). Fluorescent cells increased in number suggesting persistence of the initially homed cells. Thus, marrow cells home to lung and show persistence and an increase in number over the 2 weeks post-cell infusion. We also showed clustering of donor cells at 14 days suggestive of donor derived colonies (Fig. 2 D\&E). These data indicate that there is an increased number of stem cells homed to the lung at 24 hours of culture at the G1/S interface.

\section{Autofluorescence and Overlap of Cells}

We evaluated the capacity of either purified GFP ${ }^{+}$Lin $^{-}$Sca- $1^{+}$cells or whole bone marrow (WBM) cells to engraft in lung and demonstrate a nonhematopoietic phenotype by quantitating $\mathrm{GFP}^{+} \mathrm{CD} 45^{-}$cells in frozen or paraffin sections of lung from transplanted mice. We first established the validity of our cell tracking and identification approaches. We transplanted $250,000 \mathrm{GFP}^{+} \mathrm{Lin}^{-} \mathrm{Sca}-1^{+}$cells or the cultured volume equivalent, along with 200,000 WBM as helper cells, into $900 \mathrm{cGy}$ irradiated mice. We then evaluated the lungs 9-12 weeks after initial cell infusion. Samples were examined using a fluorescent microscope with filter sets as follows: DAPI, FITC, Texas Red and a FITC/Texas Red double bandpass. The slides were examined using all filters however the double band pass filter was heavily utilized for discriminating true fluorescent signal from autofluorescence. Since autofluorescence emits signal across many wavelengths it is seen in both the FITC and the Texas Red filters. True fluorescent signal should only be visualized in the filter designed for it. This method of distinguishing autofluorescence from true signal has been validated in the literature (33). With the doubleband pass filter two colors, green and red, are visualized simultaneously. Any autofluorescence seen in this filter appears yellow/orange (as it emits at many wavelengths) (Fig. 3). We examined our samples under confocal microscopy but found that although monochrome cameras used in confocal imaging offered superior resolution and dynamic range, they were not suitable for scoring samples as they are incapable of distinguishing true signal from autofluorescence. As stated above, we used a FITC/Texas Red double bandpass filter for scoring samples and used deconvolution microscopy for high resolution images. These images where acquired with a high resolution monochrome camera only after verification of true signal using standard filters and the double bandpass filter.

In Figure 4 A-D, DAPI positive cells (nucleus present) which are also GFP ${ }^{+}$are shown. One of the cells (4D) is also cytokeratin positive. Deconvolution fluorescent microscopy is used to 
demonstrate colocalization of DAPI, GFP and cytokeratin and this is also shown utilizing deconvolution fluorescent microscopy (Fig. 4E).

We have previously addressed the issue of autofluorescence using rhodamine (red) anti-GFP antibodies to determine whether green fluorescing cells were expressing GFP protein or were examples of autofluorescence. In summary, under the conditions of our experiments, autofluorescence was rare or not seen and if present was excluded from the counts by use of the double bandpass filter(13). The geographical location of the GFP positive cells is shown in Figure 5. Donor hematopoietic cells (GFP+CD45+), host hematopoietic cells (GFP-CD45+) and donor cells with a nonhematopoietic phenotype (GFP+CD45-) are seen distributed at different locations in the alveolar walls.

\section{Engraftment studies}

Wild type C57BL/6 mice were exposed to 900-1000 cGy whole body irradiation and then infused with either $5 \times 10^{6}$ green-fluorescent protein (GFP) positive (GFP ${ }^{+}$) WBM cells or with 250,000 lineage negative, Sca- $1^{+} \mathrm{GFP}^{+}$marrow cells plus 200,000 wild type C57BL/6 WBM cells. Three weeks later mice were injected with granulocyte colony stimulating factor (G-CSF) $(250 \mu \mathrm{g} / \mathrm{Kg})$ subcutaneously daily for 5 days. Mice were then administered intratracheal bleomycin, intramuscular cardiotoxin or no treatment with a subsequent 5 day course of G-CSF. The mice were then sacrificed 2 months after transplantation. We found that the number of CD45- donor cells in the cardiotoxin group $(n=17)$ was not significantly different from those in the non cardiotoxin group $(n=16)$ so the results from these groups have been combined. The bleomycintreated mice (2 mice) gave similar results to that seen with the cardiotoxin mice and these results were included in the combined results. In one experiment a lower dose of cytokines was utilized, again with identical results.

The number of GFP ${ }^{+} \mathrm{CD} 45^{-}$lung events varied significantly between experiments for uncultured cells (time 0 group), ranging from 0.84 to $22.5 \%$ for WBM and from 0.37 to 1.55 for Lin Sca- $1^{+}$ cells. For the evaluation of changes over time in culture, these data were normalized as a $\%$ of the time 0 values.

Values for total $\mathrm{GFP}^{+}$cells per DAPI ${ }^{+}$cell (nucleated), normalized to time 0 values are presented in Table I. The absolute mean percentage $+/$ - one standard error of the mean for total $\mathrm{GFP}^{+}$ events in the lungs at time 0 in the WBM only experiments was $22.6+/-1.8 \%$ of all DAPI ${ }^{+}$cells. The majority of these $\mathrm{GFP}^{+}$cells $(75 \%)$, were hematopoietic cells (CD45+).. When Lin ${ }^{-}$Sca- ${ }^{+}$ marrow cells were transplanted, $11+/-3$ percent of the DAPI positive events were GFP+ and of these $87.3 \%$ were $\mathrm{GFP}^{+} \mathrm{CD} 45^{+}$. When all groups were combined (WBM and Lin ${ }^{-}$Sca- $1^{+}$groups), the number of GFP+ cells per DAPI positive cells at time 0 was $21+/-1.9 \%$ and $74 \%$ of these were $\mathrm{GFP}^{+} \mathrm{CD} 45^{+}$. The changes over time as a percent of time 0 are shown in Table I. There were significant increases for $\mathrm{GFP}^{+}$lung events when either WBM or Lin ${ }^{-S} \mathrm{Sca}^{-1^{+}}$groups were infused after 24 hours culture in IL-3, IL-6, IL-11 and steel factor (G1/S) $(P<0.05)$. We were particularly interested in the GFP ${ }^{+} \mathrm{CD} 45^{-}$population of cells in the lungs of transplanted mice, since these cells represent marrow donor derived cells which no longer have a hematopoietic phenotype. As noted above, the observed events were not due to autofluorescence or overlapping cells. While the number of $\mathrm{GFP}^{+} \mathrm{CD} 45^{-}$events per $\mathrm{DAPI}^{+}$cell varied between experiments, when the results were normalized and expressed as a percent of time 0 , there was a marked increase in $\mathrm{GFP}^{+} \mathrm{CD} 45^{-}$events when 24 hour cultured marrow cells were compared to time 0 . There was then a return to baseline at 48 hours. Data from WBM, Lin Sca- $1^{+}$and the combined groups are presented in Figure 6 . See figure legends for statistics.

When the same data was analyzed and presented per culture experiment, instead of based upon the individual transplanted mice, the same conclusions were reached; there was a significant increase in $\mathrm{GFP}^{+} \mathrm{CD} 45^{-}$cells/DAPI ${ }^{+}$cell in the lungs of mice transplanted with 24 hour cultured cells. This increase was not seen at 48 hours (Fig. 7).

We have also confirmed this 24 hour G1/S increase in donor-derived nonhematopoieitc lung cells using a different and simpler model in which mice were irradiated with 900 cGy whole body 
irradiation and then sacrificed 6 weeks later. No mobilization was used. We again saw a marked increase in events in the 24 hour LI-3, IL-6, IL11 and steel factor cultured group (Figure 8).

There was a significant increase $(p<0.05)$ in the number of $\mathrm{GFP}^{+} /$cytokeratin ${ }^{+}$cells (donor-derived pulmonary epithelial cells) in the lungs of mice transplanted with 24 hour cultured cells. This level returned to baseline in the 48 hour group (Fig. 9).

\section{Real Time RT- PCR for Lung Markers}

Total RNA was isolated from Lin-Sca-1+ murine marrow cells at 0,24 and 48 hours of culture in IL-3,IL-6, IL-11 and steel factor and Real Time ( RT-PCR) carried out to determine mRNA levels for different lung specific proteins. mRNA for Clara-cell protein, cytokeratin 14, cytokeratin 5 and surfactant B were not detected at any time point, while Pecam was detected but unchanged at the different time points. Col 1 was also detected at time 0 and was decreased thereafter.

\section{Marrow/Lung cell fusion studies}

In lethally-irradiated mice that received WBM cells from female donors, we found no cells within their lungs that were GFP+ and XXXY+. Samples were analyzed for the presence of cells of both donor (female) and recipient (male) origin and were defined as nucleated cells (DAPI+) that were $\mathrm{XXXY}+$. Five to $10 \mathrm{HPF}$ were analyzed from each of the 5 male bone marrow recipients using both standard fluorescence and deconvolution microscopy. Over 5,000 total nuclei were visualized. Three dimensional images of some cells were created from a 25 stack layer $(0.4 \mu \mathrm{m} / \mathrm{layer}) \mathrm{Z}$-stack to rule out fluorescent signal from adjacent cells. Lung samples from female recipients were also analyzed in a similar fashion for the presence of fused cells $(X X X X+)$. In addition, lethally-irradiated female mice that received WBM cells from female donors had no $G F P+X X X X+$ cells within the lungs. These findings suggest that fusion did not significantly contribute to the presence of donor marrow-derived lung cells.

\section{Discussion:}

The phenotype of bone marrow stem cells is labile with a cytokine induced passage through cell cycle. It shows reversible modulation, and this has led to the concept that marrow stem cells may be regulated on a continuum, rather than in a hierarchy (17-21). These observations have, until now, been restricted to hematopoietic phenotypes with reversibility of function within the hematopoietic tissue. In their "quantitative stem cell modeling" Roeder et al (32) describe "withintissue plasticity", which is consistent with our previous studies on the hematopoietic phenotype of cycling stem cells. Kirkland (31), with his phase space model of hematopoiesis, has also emphasized the lability of the marrow stem cell phenotype.

The present data indicate that a cycle related phenotype modulation of marrow stem cells extends to nonhematopoietic cells and tissues. We have shown here that engrafting marrow stem cells in the G1/S interface have a capacity to form non-hematopoietic cells in lung tissue that is approximately three times that of the quiescent freshly isolated noncultured cells (Figs 57). This increased capacity to make lung cells is not fixed, but changes over time and at 48 hours of culture (lateS/G2) has returned to baseline. Thus this represents a reversible shift in differentiation tied to cell cycle.

Our results have to be viewed within the context of the controversial area of stem cell plasticity. Major criticisms of this area of research have been raised including the robustness of the phenomena, the accuracy of cell identification, and the difficulty in demonstrating transdifferentiation (34-36) In addition, it has been suggested that if fusion is involved or if the studies have not been carried out clonally, the phenomena is meaningless. We have addressed these issues recently in a perspective entitled, "Ignoratio Elenchi" (37). This means red herrings. 
To reiterate: robustness is a relative phrase, clonal studies address heterogeneity, and many investigators have appropriately identified donor cells in their experiments.

Furthermore, fusion is simply a mechanism to an end; operative in some models and not in others, Fusion appears not to be operative in the context of the studies presented here.

We have specifically addressed the concerns of auto fluorescence and overlapping cells in our studies $(38,13)$. In Figure 4 we show colocalization of cytokeratin and GFP signals. We have not found overlapping cells to be a confounding variable. In previously reported work, we have shown a virtually total concordance of green GFP signal with red-rhodamine anit-GFP signal from transplanted cells and in our studies the rare autofluorescent event is screened out from counting by use of the double bandpass filter, as illustrated in Figure 3.

These studies indicate that marrow cells produce nonhematopoietic cells at varying levels depending upon the experimental setup, but, in general, in the $3-5 \%$ range (13). Despite this variability in total numbers per section, there was a highly reproducible increase in lung donor derived nonhematopoietic cells, when cells transplanted in early-S phase were compared to cells transplanted immediately after isolation. A portion of these cells marked with cytokeratin and, thus, were pulmonary epithelial lung cells. These cytokeratin cells also showed a significant increase when G1/S phase cells were transplanted.

The relationship of homing to the subsequent engraftment events remains unclear. In nonirradiated mice, there was an increase in homed Lin Sca- $1^{+}$cells in early-S phase. This is the same time point in culture in which we see a later increase in donor marrow-derived cells with a nonhematopoietic or epithelial phenotype. The 1 and 2 week time points carried out in irradiated mice indicate that the cells which homed to lung persisted and increased in number, but do not tell us whether these cells were the critical cells for the later engraftment events or whether cells which initially homed to marrow were largely responsible for the donor lung cells with nonhematopoietic phenotype observed at 2 months post engraftment. Marrow cells which restore liver cells may first need to engraft in marrow (9). The reproducible augmentation seen with GCSF mobilization (13), which we have previously reported, is supportive of this view. Initial homing and later mobilization from the marrow may both be involved in the final engraftment results.

The underlying mechanism for determining the lung hotspot remains an open question. Lung specific markers on marrow stem cells at the hotspot were undetectable, but this, does not address the potential of the cells at that point in time. During cell cycle passage chromatin/histone coverage continues to change so that different promoter regions are susceptible to transcriptional regulation (39-43). Changes in the final cell lineage after transplantation could then be determined by activation of specific promoters that could directly or indirectly lead marrow cells to form cells with a lung phenotype. A similar sequence of events may occur with the megakaryocyte hotspot observed when lineage negative rhodamine low Hoechst low cells are cultured in thrombopoietin, FLT3I and steel factor and then subcultured in G-CSF, GM-CSF and steel factor at the G1/S interface (26). It is also possible that at certain phases of cell cycle the cell expresses specific receptors which can receive external signals allowing for eventual lung cell differentiation. An increased propensity for cell fusion at particular points in cell cycle could also explain the increased number of $\mathrm{GFP}^{+} \mathrm{CD} 45^{-}$or $\mathrm{GFP}^{+}$cytokeratin ${ }^{+}$lung events after transplantation, however our studies reported here, and those of others, rule against cell-cell fusional events $(44,45)$. More subtle fusional events with transfer of cellular elements remains a possibility.

In summary, the present data indicate that the capacity of marrow cells to form cells in lung and adopt the phenotype of lung cells reversibly varies with time in cytokine culture and phase of cell cycle. This suggests that the continuum concept for marrow stem cells can be extended to nonhematopoietic cells. One could speculate that there may be differentiation hotspots for other nonhematopoietic cell types in the body and that these may be identified by studies of highly synchronized cycling stem cells.

\section{Materials and Methods}


Six-eight week old female or male C57BL/6 (H2Kb) or C57BL/-TgN(ACTbEGFP)1Osb mice were purchased from Jackson Laboratory (Bar Harbor) and bred in our animal facility by mating heterozygous GFP positive mice to C57BL/6 mice to produce GFP positive transgenic mice. Animals were certified to be pathogen-free. All animals were housed in micro-insulator cages, in a conventional clean facility for at least one week prior to experimental use. All studies were approved by the Institutional Animal Care and Use Committee of Roger Williams Medical Center,. Animals were given ad libitum access to food and water. C57BL/6 mice were also obtained from Taconic Farms (Germantown, N.Y.)

WBM transplants. Male C57BL/6-TgN(ACTbEGFP)1Osb mice (GFP positive) were anesthetized followed by cervical dislocation. Bone marrow was flushed from tibiae, femurs, and iliac crests with phosphate-buffered saline (PBS) supplemented with $5 \%$ heat inactivated fetal calf serum (HI FCS); Hyclone, Logan, VT) using a 22.5-gauge needle. Host C57BL/6 male mice received lethal irradiation with $900 \mathrm{cGy}$ total body irradiation (TBI) give as a single dose or 1000 cGy TBI given as a split dose of 500 cGy 3 to 4 hours apart. Irradiation was done using a linear accelerator or a gammacell 40 irradiator (MDS Nordion, Canada). Each host animal received $5 \times 10^{6}$ WBM from the GFP donors.

Stem cell harvest . Six to 8-week old male mice were killed by cervical dislocation. BM was collected from spines, femurs, tibiae, and iliac crests. Bones were ground in phosphate-buffered saline (PBS) supplemented with $5 \%$ heat inactivated fetal calf serum (HI FCS); (Hyclone, Logan, VT) using a mortar and pestle. The bone fragments were washed multiple times and the supernatant cell suspension and wash fractions strained through a 40- $\mu \mathrm{m}$ filter to remove large bone particles. High lipid concentrations were reduced by centrifugation and resuspension of the cells in fresh buffer. The cellular suspension was incubated on ice for 3 minutes, so that small bone particles could settle out. The cell supernatant was then diluted to $10^{7}$ cells $/ \mathrm{ml} \mathrm{PBS,} 5 \% \mathrm{HI}$ FCS.

Lineage negative cells were isolated as previously described (25). Low density marrow cells $\left(<1.077 \mathrm{~g} / \mathrm{cm}^{3}\right)$ were isolated by discontinuous density centrifugation using 1-Step for animals (Accurate Chemical and Scientific Corp., Westbury, NY) or Optiprep ( Accurate Chemical and Scientific Corp., Westbury, NY), washed, and resuspended at $10^{8}$ cells $/ \mathrm{ml}$ in PBS $5 \%$ HI FCS. Cells were labeled with a cocktail of primary rat antibodies: anti-B220 (B cells), anti-MAC-1 (macrophages and neutrophils), anti-GR1 (neutrophils), anti-Lyt-2 (CD8 T-cells), anti-L3T4 (CD4T-cells) and Ter119 (erythrocytes precursors). After 15-minute incubation on ice, the labeled cells were washed in PBS 5\% HI FCS and resuspended at $10^{8}$ cells $/ \mathrm{ml}$ in PBS $5 \% \mathrm{HI} \mathrm{FCS}$. The cells were incubated with sheep anti-rat IgG conjugated immunomagnetic polystyrene spheres (M-450 Dynabeads; Dynal, Lake Success, NY) according to manufacturer instructions. Immunomagnetic bead-rosetted cells were removed using a magnetic particle concentrator (Dynal, MPC-6) and the unrosetted cells remaining in suspension were harvested. The beads were washed three times and the supernatant pooled with the cell suspension.

Lin Sca-1 ${ }^{+}$Separation. Immunomagnetically lineage depleted cell suspensions were washed and resuspended at cell concentrations of 3 to $5 \times 10^{6}$ cells per $\mathrm{ml}$ in PBS $5 \% \mathrm{HI}$ FCS and incubated with biotin anti-mouse Sca-1 (BD Pharmingen; stock $0.5 \mathrm{mg} / \mathrm{ml}$ ) antibody at a concentration of $2.5 \mu \mathrm{g} / \mathrm{ml}$ for 20 minutes on ice. The cells were washed again resuspended at 3 to $5 \times 10^{6}$ cells per $\mathrm{ml}$ in PBS $5 \% \mathrm{HI} \mathrm{FCS}$ and incubated with streptavidin allophyocyanin (Molecular Probes; stock $1 \mathrm{mg} / \mathrm{ml}$ ) at a concentration of $5 \mu \mathrm{g} / \mathrm{ml}$ for 20 minutes on ice in the dark. The cells were then washed with ice-cold PBS 5\% HI FCS and resuspended in PBS containing 1 $\mu \mathrm{g} / \mathrm{ml}$ propidium iodide (PI; Sigma Chemical Co., St. Louis, MO). The sample was filtered through a $35 \mu \mathrm{m}$ small blue cap filter (Falcon Cat \# 2235). Fluorescence-activated cell sorting was performed on a MoFlo cell sorter (Cytomation, Fort Collins, CO). Lineage negative cells were sequentially selected for sorting as $\mathrm{PI}^{-}$and Sca-1 ${ }^{+}$. 
Cytokine stimulated cell culture. WBM $\left(1-5 \times 10^{6} / \mathrm{ml}\right.$.) or Lin ${ }^{-}$Sca- $1^{+}$marrow cells were established in Teflon (non-adherent) bottle cultures with DMEM $+15 \% \mathrm{HI} F C S+1 \%$ penicillin + $1 \%$ streptomycin $+1 \%$ L-glutamine and cytokines at the following concentrations; recombinant mouse (rm) IL-3, $50 \mathrm{U} / \mathrm{ml}$, recombinant mouse IL-11, $50 \mathrm{ng} / \mathrm{ml}$, rmlL-6, $50 \mathrm{U} / \mathrm{ml}$ and $\mathrm{rm}$ steel factor $50 \mathrm{ng} / \mathrm{ml}$. Cultures were harvested at 0 hour (time 0 , before culture) 24, 40, and 48 hours. In one experiment 100 fold lower levels of cytokines were used with qualitatively similar results. The cells were washed, resuspended at $2 \times 10^{6}$ cells $/ \mathrm{ml}$ (based on culture volume) in sterile PBS, and then immediately infused via tail vein injection.

Homing Assay. Lin-Sca-1+ cells were labeled with 5(6)-carboxyfluorescein diacetate Nsuccinidyl ester (CFSE) (Molecular Probes, Eugene, OR) (46). Cells were suspended at a concentration of $1-5 \times 10^{6} \mathrm{cells} / \mathrm{ml}$ in pre-warmed PBS containing $2 \mu \mathrm{M}$ CFSE. Labeling was carried out at $37^{\circ} \mathrm{C}$ for 15 minutes and stopped by adding several volumes of ice-cold Hanks' balanced salt solution (HBSS) containing $10 \%$ fetal calf sera (FCS). CFSE labeled cells were recovered after centrifugation and resuspended at a concentration of $1 \times 10^{6} / \mathrm{ml}$ in sterile saline. Cells were kept on ice and protected from light until infusion. The presence of CFSE labeled cells in host tissues was determined three hours after cell infusion either by flow cytometry (marrow cells) or by fluorescent microscopy of frozen sections of lung, liver, spleen, heart, thymus, and skeletal muscle.

Persistence Assay. Cell infusions were structured as above but $\mathrm{GFP}^{+}$cells were utilized in order to track cells at 7 and 14 day intervals after cell infusion. Cell tracking was accomplished by scoring fluorescent events on frozen lung sections.

Determination of capacity of cycling marrow cells to produce lung cells. Whole uncultured marrow or Lin Sca- $1^{+}$GFP $^{+}$marrow cells or cultured (24 or 48 hours) GFP ${ }^{+}$marrow cells (see above) were infused via tail vein into C57BL/6 hosts that received 900 or 1000cGy irradiation (split dose 3 or 4 hours apart) on day 0. Recipient mice then received G-CSF ( $250 \mu \mathrm{g} / \mathrm{kg}$ ) for 5 days followed by either no injury, intratracheal bleomycin (Blenoxane ${ }^{\circledR}$, Britol-Myers-Squibb Princeton, NJ 2 units $/ \mathrm{kg}$ ) or intramuscular cardiotoxin (10mM final) into anterior tibialis muscle followed by another 5 days of G-CSF. Two months after cell infusion mice were sacrificed and lungs evaluated for $\mathrm{GFP}^{+}$events. In one experiment mice were engrafted and analyzed 6 weeks later without other interventions.

Organ harvest. Mice were anesthetized using intraperitoneal ketamine/xylazine. Red blood cells were removed from the lungs by slow perfusion with PBS into the right ventricle, followed by perfusion of the left ventricle. Ice-cold $4 \%$ paraformaldehyde was infused into the lungs through a small hole in the trachea. A blunted $22^{1 / 2}$-gague needle was used to deliver the $4 \%$ paraformaldehyde. Inflation of the lungs in this fashion allowed for adequate fixation of epithelial surfaces and expanded airways and alveolar spaces, preserving morphology. Once the heart and lungs were removed, the tissues were placed into ice-cold periodate-lysineparaformaldehyde (PLP). The left lung and caudal lobe of the right lung were cut into two pieces and the cranial, middle and accessory lobes of the right lung were left intact. The lungs were fixed in PLP shaking on ice for 2-3 hours and then placed in $7 \%$ sucrose over night at $4^{\circ} \mathrm{C}$ followed by imbedding in frozen section medium the next morning pieces were kept at $-70^{\circ} \mathrm{C}$ for storage. Lungs that were to be embedded in paraffin were dehydrated through graded ethanol then mineral spirits and finally embedded in paraffin wax.

CD 45 staining. Eight micrometer lung sections were mounted on either $0.01 \%$ poly-L-lysine (Sigma, St Louis MO) or adhesive coated slides (Newcomer supply). Sections of lung were incubated at $37^{\circ} \mathrm{C}$ for 30 minutes then washed in PBS 2 times for 2 minutes at room temperature. Samples were blocked for avidin/biotin washed and incubated with primary antibody, biotin rat anti mouse CD45 (Pharmingen), at room temperature for one hour. Slides were washed three times for 5 minutes in PBS at room temperature and incubated with Texas red avidin (Vector) at room temperature for 30 minutes. The slides were then washed three times in PBS at room temperature and counter stained with Vectasheild and Dapi. 
Cytokeratin/CD45. An antigen retrieval step was necessary for cytokeratin labeling and was performed by incubating samples in $20 \%$ Triton $x-100$ for 20 minutes at room temperature. When labeling lung samples for cytokeratin and CD45 it was necessary to amplify the CD45 signal using a TSA Biotin System (PerkinElmer Life Sciences). Briefly, the samples were cut and prepared as above. After the primary antibody was washed off, the samples were incubated with streptavidin HRP for thirty minutes at room temperature, washed with $0.05 \%$ TWEEN for 5 minutes 3 times. They were incubated with Biotinyl Tyramide Reagent (Perkin Elmer Life Sciences) for 10 minutes then washed and processed as described above except that AMCA was used as a secondary for CD45. Because of this no DAPI counter stain was done.

Evaluating lung sections. Donor $\mathrm{GFP}^{+} / \mathrm{CD} 45$ - or $\mathrm{GFP}^{+} /$cytokeratin $^{+}$cells were expressed as a percentage of the total number of DAPI positive cells and were counted by fluorescence microscopy. Isotype and secondary only controls were performed for CD45 and cytokeratin. Expression of GFP and antigens stained by different fluorescent conjugated antibodies were visualized by standard fluorescent and deconvolution microscopy. In order to exclude autofluorescent cells, cells were evaluated using a double bandpass filter. CD45 and cytokeratin samples were also evaluated by confocal microscopy. The three dimensional images of cells were created from a 40 layer $(0.2 \mu \mathrm{m} /$ layer $)$ Z-stack, in order to show colocalization of green and red signals (GFP/cytokeratin).

\section{Marrow/Lung Cell Fusion Studies}

C57BL/6 mice where lethally irradiated with 900cGy TBI split dose 3 hours apart. These mice were transplanted with $5 \times 10^{6}$ WBM cells obtained from male GFP+ mice as previously described. Two months later recipient lungs were harvested, inflation fixed and paraffin embedded as previously described. Tissue analysis was done on $5-\mu \mathrm{m}$ lung sections. Samples were deparaffinized in xylene and ethanol then permeabilized with $0.3 \%$ Triton $X$ for 15 minutes. Sections were then digested with Proteinase $\mathrm{K}$ for 5 minutes at $37^{\circ} \mathrm{C}$ and fixed in $4 \%$ paraformaldehyde for 5 minutes. Prehybridization buffer, containing $150 \mathrm{mM}$ sodium chloride, 15 $\mathrm{mM}$ sodium citrate, $0.2 \mathrm{mM}$ dextran sulfate (Sigma, St. Louis, MO), $4 \mu \mathrm{g}$ murine Cot 1 DNA (Invitrogen, Carlsbad, CA) and $150 \mathrm{mM}$ dithiothreitol (DDT, Sigma), was added to each sample and incubated at $45^{\circ} \mathrm{C}$ for 1.5 hours. Y chromosome probe (A gift from Dr. Ulli Weier, Lawrence Berkeley National Laboratory, Berkeley, CA) and FITC-conjugated mouse chromosome $X$ probe (Cambrio, UK) were added to the prehybridization buffer and samples were denatured at $80^{\circ} \mathrm{C}$ for 10 minutes. Hybridization occurred overnight at $45^{\circ} \mathrm{C}$. The following day, samples were washed in $0.1 \times$ SSC ( $15 \mathrm{mM}$ sodium chloride and $1.5 \mathrm{mM}$ sodium citrate) for 1 hour at $45^{\circ} \mathrm{C}$. Samples were blocked using a $5 \%$ fetal calf serum $/ 5 \%$ non fat milk solution for 15 minutes. The $Y$ probe was detected using anti-digoxigenin rhodamine $F(a b)$ fragments (Roche, Indianapolis, IN), diluted 1:33 in 1 XPBS/2\% bovine serum albumin and added to each sample for 2 hours. Samples were washed in 1XPBS and counterstained with Vectashield and DAPI.

Evaluating lung sections for the presence of fused marrow/lung cells Samples from female to male transplants were analyzed for the presence of cells of both donor (female) and recipient (male) origin and were defined as nucleated cells (DAPI+) that were $X X X Y+$. Five to $10 \mathrm{HPF}$ were analyzed from each of the 5 male bone marrow recipients using both standard fluorescence and deconvolution microscopy. Over 5,000 total nuclei were visualized. Three dimensional images of some cells were created from a Z-stack(25-layer) to rule out fluorescent signal from adjacent cells. Lung samples from female to female transplants were also analyzed in a similar fashion for the presence of fused cells ( $X X X X+)$.

\section{Real Time RT-PCR}

Total RNA was isolated from cultured cells, using RNeasy®Micro Kit (Qiagen Inc. Valencia, CA). Real Time reverse transcription-polymerase chain reaction (Real Time RT-PCR) was performed in a two step reaction. Reverse transcription was achieved with the TaqMan ${ }^{\circledR}$ RT Reagents kit ( 
Applied Biosystems, Foster City, CA) and the PCR reaction was performed using samplings from the same cDNA aliquot for multiple genes. Reactions for each specific gene were performed in triplicate to ensure reliability of data. Applied Biosystems' predeveloped TaqMan® Gene Expression Assays were used in the PCR reaction for gene expression analysis. The TaqMan ${ }^{\circledR}$ assay is a 20X concentrated nucleotide mix which includes 2 unlabeled PCR primers (900nM each final concentration) and $1 \mathrm{FAM}^{\mathrm{tm}}$ dye labeled TaqMan ${ }^{\mathrm{B} M G B}$ probe (250nM final concentration). The PCR reaction was carried out with the $2 X$ TaqMan ${ }^{\circledR}$ PCR mastermix (Applied Biosystems) and 20X assay mix in 25ul reactions in the AB17000 Sequence Detection System (Applied Biosystems) on the same thermal profile of $50^{\circ} \mathrm{Cx} 2 \mathrm{~min} ., 95^{\circ} \mathrm{C} \times 10 \mathrm{~min}$., 40 cycles $\left(95^{\circ} \mathrm{Cx}\right.$ $15 \mathrm{sec} ., 60^{\circ} \mathrm{Cx} 1 \mathrm{~min}$.). Beta- 2 microglobulin was used as an endogenous control in conjunction with the genes of interest.

Statistics. Statistics were done using ANOVA for analysis of variance, if ANOVA showed a statistical significant result, posthoc tests were performed with Turkey's test for all pairs comparisons. Dunnett's test was used for comparisons of 24 and 48 hours against 0 hour.

Acknowledgements:

This publication was made possible by Grant Number P20RR018757-04 from the National Center for Research Resources (NCRR), a component of the National Institutes of Health (NIH), grant number 1R01DK61858-03 and grant number 1R01HL73747-02. Add KO8'S.

\section{References:}

1. Quesenberry, P.J., and L. Levitt. 1979. Hematopoietic stem cells. N Engl J Med. 301:755760.

2. Quesenberry, P.J., and L. Levitt. 1979. Hematopoietic stem cells (second of three parts). $N$ Engl J Med. 301: 819-823.

3. Quesenberry, P.J., and L. Levitt. 1979. Hematopoietic stem cells (third of three parts). N Engl J Med. 301:868-872.

4. Ferrari, G., G. Cusella-DeAngelis, M. Coletta, E. Paolucci, A. Stornaiuolo, G. Cossu, and F. Mavilio. 1998. Muscle regeneration by bone marrow-derived myogenic progenitors. Science 279:1528-1530.

5. Gussoni, E., Y. Soneoka, C.D. Strickland, E.A. Buzney, M.K. Khan, A.F. Flint, L.M. Kunkel and R.C. Mulligan. 1999. Dystrophin expression in the $\mathrm{mdx}$ mouse restored by stem cell transplantation. Nature 401:390-394.

6. Wakitani, S., T. Saito and A.L. Caplan. 1995. Myogenic cells derived from rat bone marrow mesenchymal stem cells exposed to 5-azacytidine. Muscle Nerve. 18:1417-1426.

7. Abedi, M., D.A. Greer, B. Foster, G.A. Colvin, J.A. Harpel, D.A. Demers, J. Pimentel, M.S. Dooner, and P.J. Quesenberry. 2005. Critical variables in the conversión of marrow cells to skeletal muscle. Blood. 106:1488-1494.

8. Petersen, B.E., W.C. Bowen, K.D. Patrene, W.M. Mars, A.K. Sullivan, N. Murase, S.S. Boggs, J.S. Greenberger and J.P. Goff. 1999. Bone marrow as a potential source of hepatic oval cells. Science. 284:1168-1170.

9. Lagasse E., H. Connors, M. Al-Dhalimy, M. Reitsma, M. Dohse, L. Osborne, X. Wang, M. Finegold, I.L. Weissman and M. Grompe. 2000. Purified hematopoietic stem cells can differentiate into hepatocytes in vivo. Nat Med. 6:1229-1234.

10. Theise N.D, S. Badve, R. Saxena, O. Henegariu, S. Sell, J.M. Crawford and D.S. Krause. 2000. Derivation of hepatocytes from bone marrow cells in mice after radiation-induced myeloblation. Hepatology. 31:235-240.

11. Krause, D.S., N.D. Theise, M.I. Collector, H.S. Henegariu, R. Gardner, S. Neutzel, and S.J. Sharkis. 2001. Multi-organ, multi-lineage engraftment by a single bone marrow-derived stem cell. Cell. 105:369-377. 
12. Kotton, D.N., B.Y. Ma, W.V. Cordoso, E.A. Sanderson, R.S. Summer, M.C. Williams, and A. Fine. 2001. Bone-marrow derived cells as progenitors of alveolar epithelium. Development. 128:5181-5188.

13. Aliotta, J.M., P. Keaney, M. Passero, M.S. Dooner, J. Pimentel, D. Greer, D. Demers, B. Foster, A. Peterson, G. Dooner, N.D. Theise, M. Abedi, G.A. Colvin, and P.J. Quesenberry. 2006. Bone marrow production of lung cells: the impact of G-CSF, cardiotoxin, graded doses of irradiation, and subpopulation phenotype. Exp Hematol. 34:320-241.

14. Cerny, J., M. Dooner, C. McAuliffe, H. Habibian, K. Stencil, V. Berrios, J. Reilly, J. Carlson, A.M. Cerny, A.M., d'Hondt, B. Benoit, J.F. Lambert, G. Colvin, S. Nilsson, P. Becker and P. Quesenberry. 2002. Homing of purified murine lymphohematopoietic stem cells: A cytokineinduced defect. J. Hematother. Stem Cell Res. 11:913-922.

15. Szilvassy, S.J., M.J. Bass, G. Van Zant, and B. Grimer. 1999. Organ-selective homing defines engraftment kinetics of murine hematopoietic stem cells and is compromised by ex vivo expansion. Blood. 93:1557-1566.

16. Habibian, H.K., S.O. Peters, C.C. Hsieh, J. Wuu, K. Vergilis, C.I. Grimaldi, J. Reilly, J.E. Carlson, A.E. Frimberger, F.M. Stewart, and P.J. Quesenberry. 1998. The fluctuating phenotype of the lymphohematopoietic stem cell with cell cycle transit. J. Exp. Med. 188:393-398.

17. Quesenberry, P., M. Abedi, M. Dooner, G. Colvin, F.M. Sanchez-Guijo, J. Aliotta, J. Pimentel, G. Dooner, D. Greer, D. Demers, P. Keaney, A. Peterson, L. Luo, and B. Foster. 2005. The marrow stem cell continuum: stochastic determinism. Folia Histochem Cytobiol. 43:187-190.

18. Quesenberry, P.J., G.A. Colvin, M. Abedi, G. Dooner, M. Dooner, J. Aliotta, P. Keaney, L. Luo, D. Demers, A. Peterson, B. Foster, and D. Greer. 2005. The stem cell continuum. Ann NY Acad Sci. 1044:228-235.

19. Quesenberry, P.J., G.A. Colvin, and J.F. Lambert. 2002. The chiaroscuro stem cell: a unified stem cell theory. Perspective, Blood. 100:4266-4271.

20. Quesenberry P.J., G.A. Colvin, M. Abedi, J.F. Lambert, B. Moore, D. Demers, D. Greer, C. McAuliffe, M. Dooner, L.G. Lum, E. Badiavas and V. Falanga. 2003. The marrow stem cell: the continuum. Bone Marrow Transplantation. 32:S19-22.

21. Quesenberry, P.J. 2006. The Continuum Model of Stem Regulation. Current Opinion in Hematotology. In press.

22. Lambert, J.F., M. Liu, G.A. Colvin, M. Dooner, C.I. McAuliffe, P.S. Becker, B.G. Forget, S.M. Weissman, and P.J. Quesenberry. 2003. Marrow stem cells shift gene expression and engraftment phenotype with cell cycle transit. J. Exp. Med. 197(11):1563-1572.

23. Becker, P.S., S.K. Nilsson, Z. Li, V.M. Berrios, M.S. Dooner, C.L. Cooper, C.C. Hsieh, P.J. Quesenberry. 1999. Adhesion receptor expression by hematopoietic cell lines and murine progenitors: modulation by cytokines and cell cycle status. Exp. Hematol. 27:533-541.

24. Berrios, V.M., G.J. Dooner, G. Nowakowski, A. Frimberger, H. Valinski, P.J. Quesenberry and P.S. Becker. 2001. The molecular basis for the cytokine-induced defect in homing and engraftment of hematopoietic stem cells. Exp. Hematol. 29(11):1326-1335.

25. Colvin, G.A., J.F. Lambert, B.E. Moore, J.E. Carlson, M.S. Dooner, M. Abedi, J. Cerny, and P.J. Quesenberry. 2004. Intrinsic hematopoietic stem cell/progenitor plasticity: Inversions. J Cell Physiol. 199:20-31.

26. Colvin G.A., M.S. Dooner, G.J Dooner, F.M. Sanchez-Guijo, D.A. Demers, M. Ramanathan, S. Chung, S. Pascual, P.J. Quesenberry. 2006. The stem cell Continuum:differentiation hotspots. Exp. Hematol. In press.

27. Bradford, G.B., B. Williams, R. Rossi, I. Bertoncello. 1997. Quiescence, cycling, and turnover in the primitive hematopoietic stem cell compartment. Exp. Hematol. 25(5):445-453.

28. Cheshier, S.H., S.J. Morrison, X. Liao, I.L. Weissman. 1999. In vivo proliferation and cell cycle kinetics of long-term self-renewing hematopoietic stem cells. Proc. Natl. Acad. Sci. USA, 96(6):3120-5.

29. Pang, L., P.V. Reddy, C.I. McAuliffe, G. Colvin, and P.J. Quesenberry. 2003. Studies on BrdU labeling of hematopoietic cells: stem cells and cell lines. J. Cell. Physiol. 197(2):251-60. 
30. Fleming, W.H., E.J. Alpern, N. Uchida, K. Ikuta, G.J. Spangrude and I.L. Weissman. 1993. Functional heterogeneity is associated with the cell cycle status of murine hematopoietic stem cells, J Cell Biol. 122(4):897-902.

31. Kirkland, M.A. 2004. A phase space model of hemopoiesis and the concept of stem cell renewal. Exp Hematol. 32:511-519.

32. Roeder, I., L.M. Kamminga, K. Brasel, B. Dontje, G. deHaan, and M. Loeffler. 2005. Competitive clonal hematopoiesis in mouse chimeras explained by a stochastic model of stem cell organization. Blood. 105:609-616.

33. Brazelton T.R., H. M. Blau. 2005. Optimizing Techniques For Tracking Transplanted Stem Cells In Vivo. Stem Cells. 23:1261-1265.

34. Anderson, D.J., F.H. Gage, and I.L. Weissman. 2001. Can stem cells cross lineage boundaries? Nat Med. 7:393-395.

35. Lemischka I. 2002. A few thoughts about the plasticity of stem cells. Exp Hematol. 30: 848852.

36. Wagers A.J., and I.L. Weissman. 2004. Plasticity of adult stem cells. Cell. 116:639-648.

37. Quesenberry, P.J., G. Dooner, M. Dooner, and M. Abedi. 2005.Ignoration Elenchi: Red Herrings in Stem Cell Rearch. Science. 308:1121-1122.

38. Kotton, D.N., A.J. Fabian, and R.C. Mulligan. 2005. Failure of bone marrow to reconstitute lung epithelium. Am. J. Respir Cell Mol Biol. 33(4):328-334.

39. Cerny, J., and P.J. Quesenberry. 2004. Chromatin remodeling and stem cell theory of relativity. J Cell Physiol. 9999:1-17.

40. Jiménez, G., S.D. Griffiths, A.M. Ford, M.F. Greaves, and T. Enver. 1992. Activation of the beta-globin locus control region precedes commitment to the erythroid lineage. Proc Natl Acad Sci USA. 89(22):10618-10622.

41. Kontaraki, J., H.H. Chen, A. Riggs, and C. Bonifer. 2000. Chromatin fine structure profiles for a developmentally regulated gene: reorganization of the lysozyme locus before transactivator binding and gene expression. Genes Dev. 14(16):2106-2122.

42. Bonifer C. 1999. Long-distance chromatin mechanisms controlling tissue-specific gene locus activation. Gene. 238(2):277-289. Review.

43. Maes, J., L.P. O'Neill, P. Cavelier, B.M. Turner, F. Rougeon, and M. Goodhardt. 2001. Chromatin remodeling at the Ig loci prior to $V(D) J$ recombination. J Immunol. 167(2):866-874.

44. Wang, X., H. Willenbring, Y. Akkari, Y. Torimaru, M. Foster, M. Al-Dhalimy, E. Lagasswe, M. Finegold, S. Olson, and M. Grompe. 2003. Cell fusion is the principle source of bone-marrowderived hepatocytes. Nature. 422:897-901.

45. Harris, R.G., E.L. Herzog, E.M. Bruscia, J.E. Grove, J.S.Van Arnam, and D.S. Kraus. 2004. Lack of a fusion requirement in bone marrow derived epithelia. Science. 305:90-93.

46. Weston SA, CR Parish.1990. New Fluorescent dyes for lymphocyte migration studies analysis by flow and fluorescent microscopy. J Immunol Meth 133:87. 
Figure 1

A

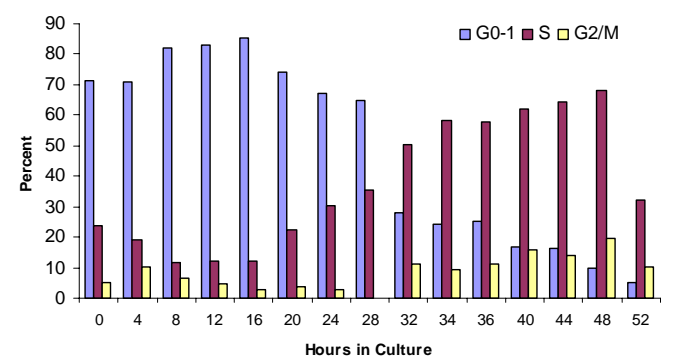

C

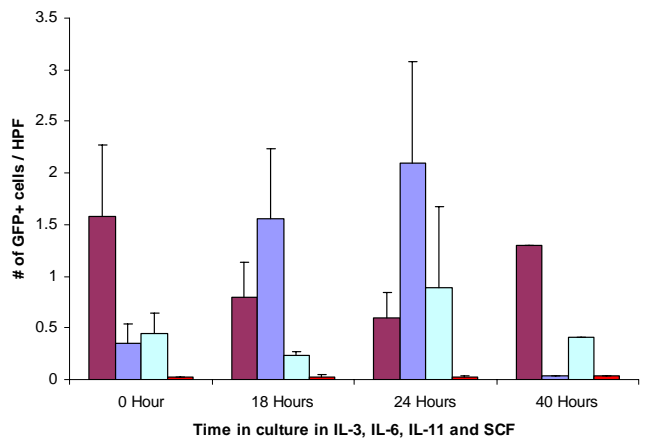

B

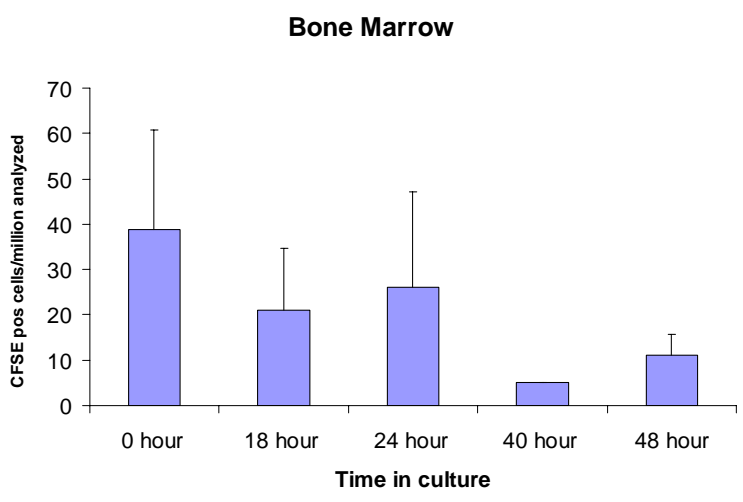

D

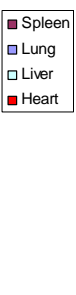

Homed events to lung by fluorescent microscopy

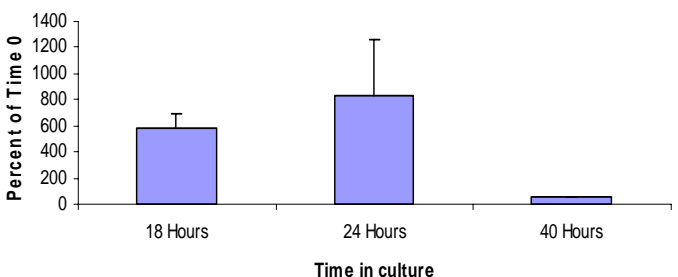

Figure 2

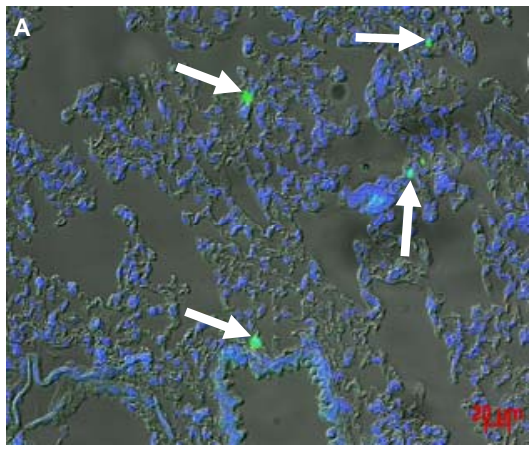

3 hours post infusion

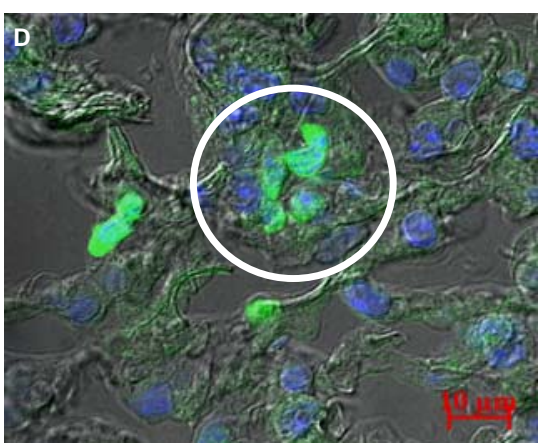

Clustering of positive cells- 14 days post infusion

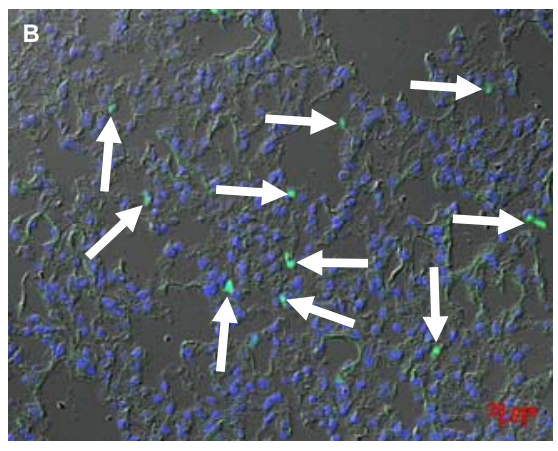

7 days post infusion

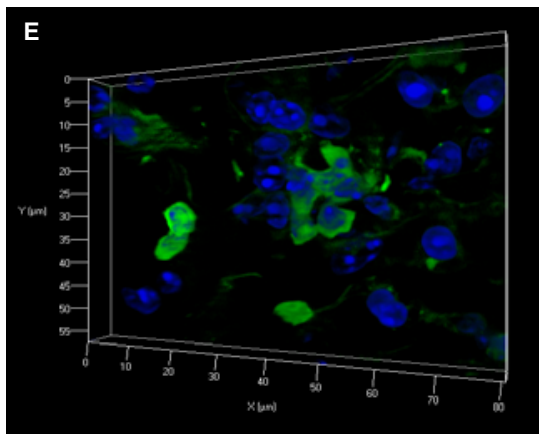

3D deconvolution of $\mathrm{D}$.

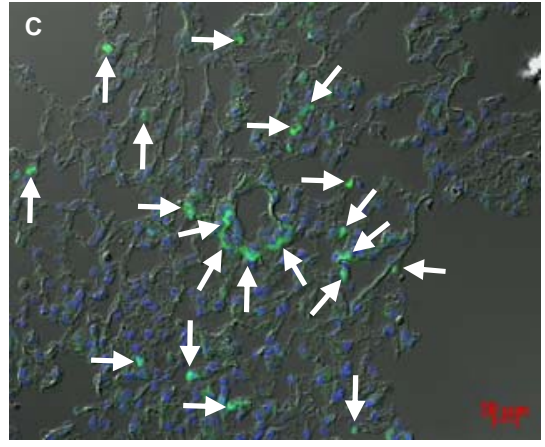

14 days post infusion 
Figure 3
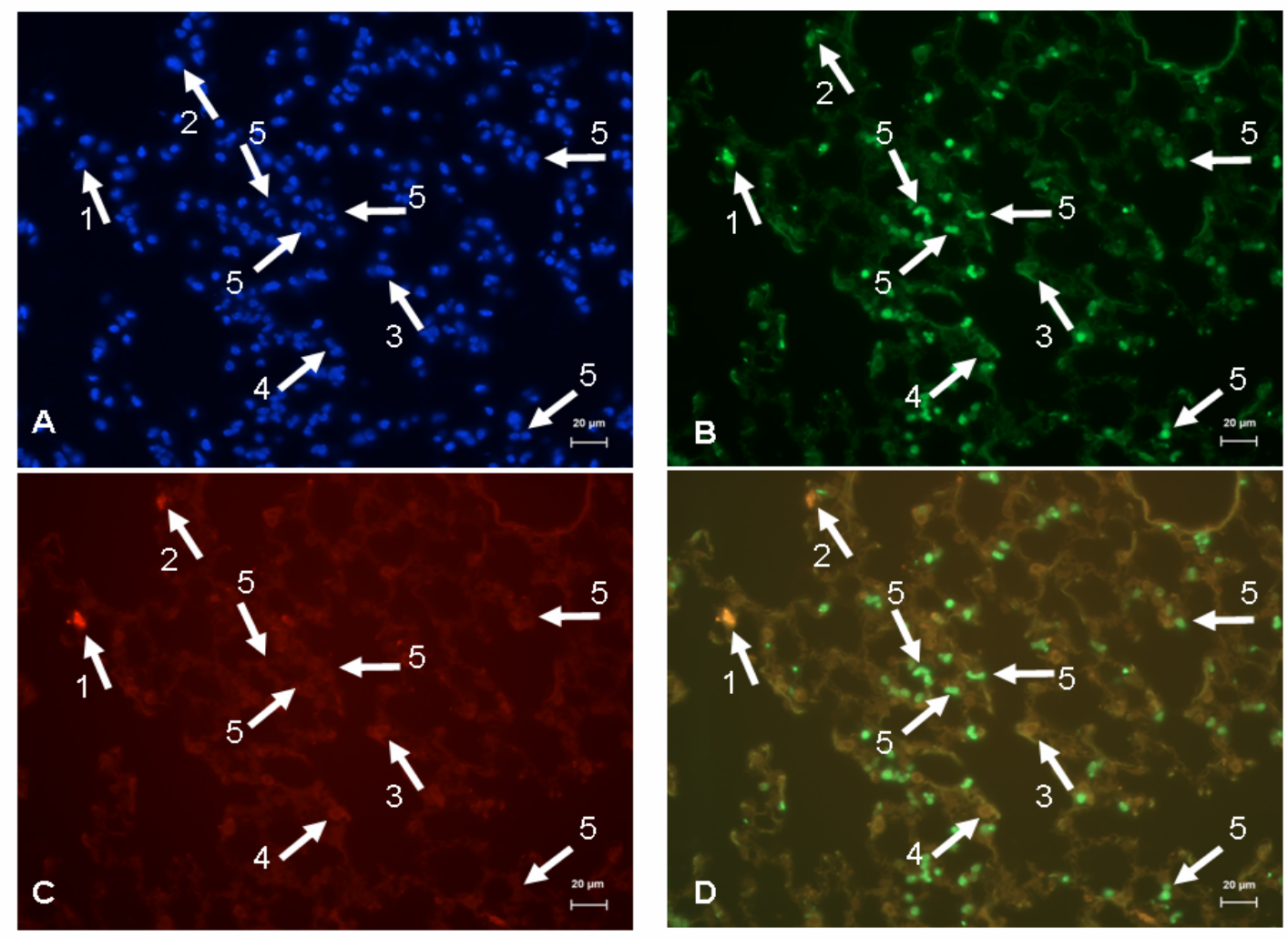

Figure 4
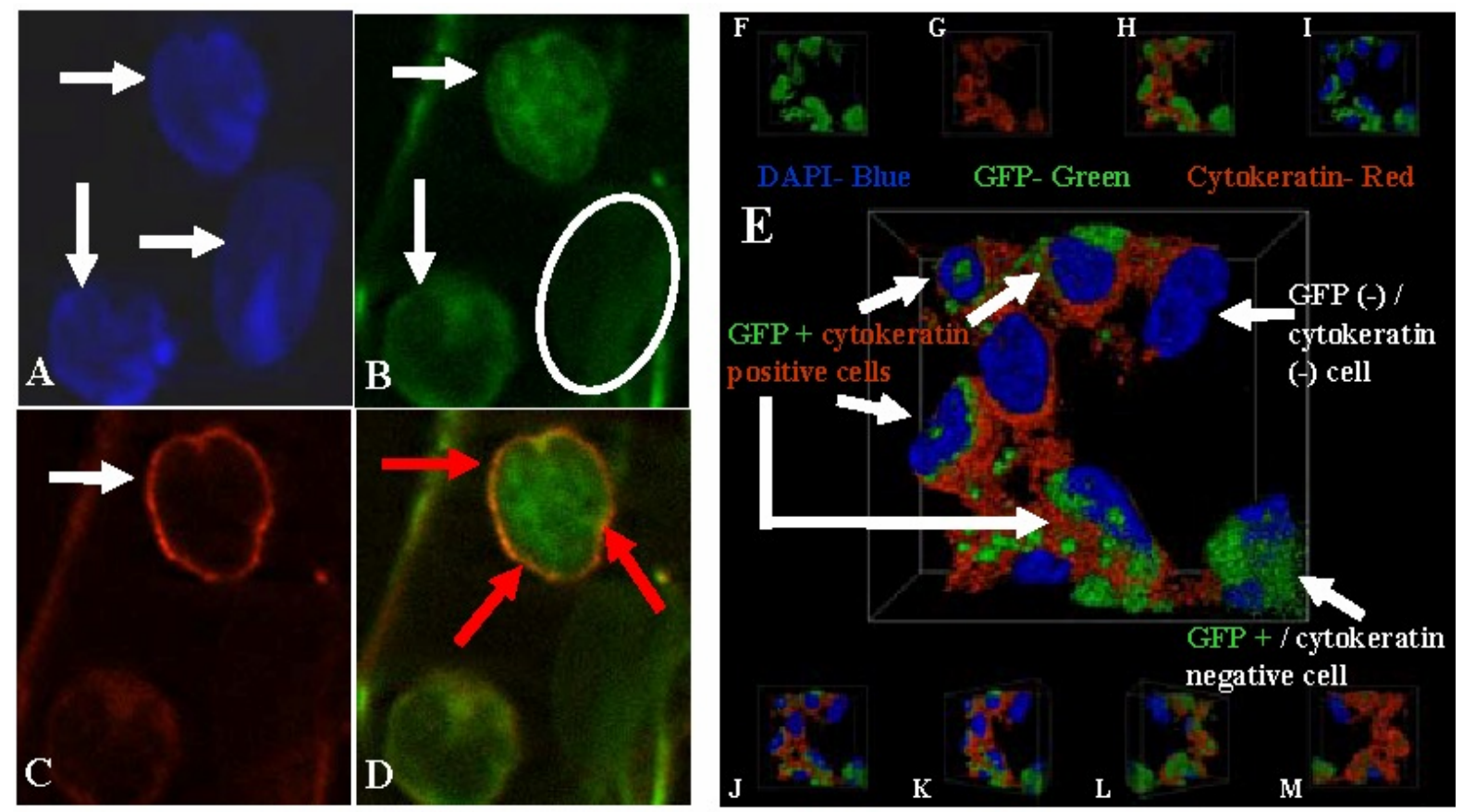
Figure 5

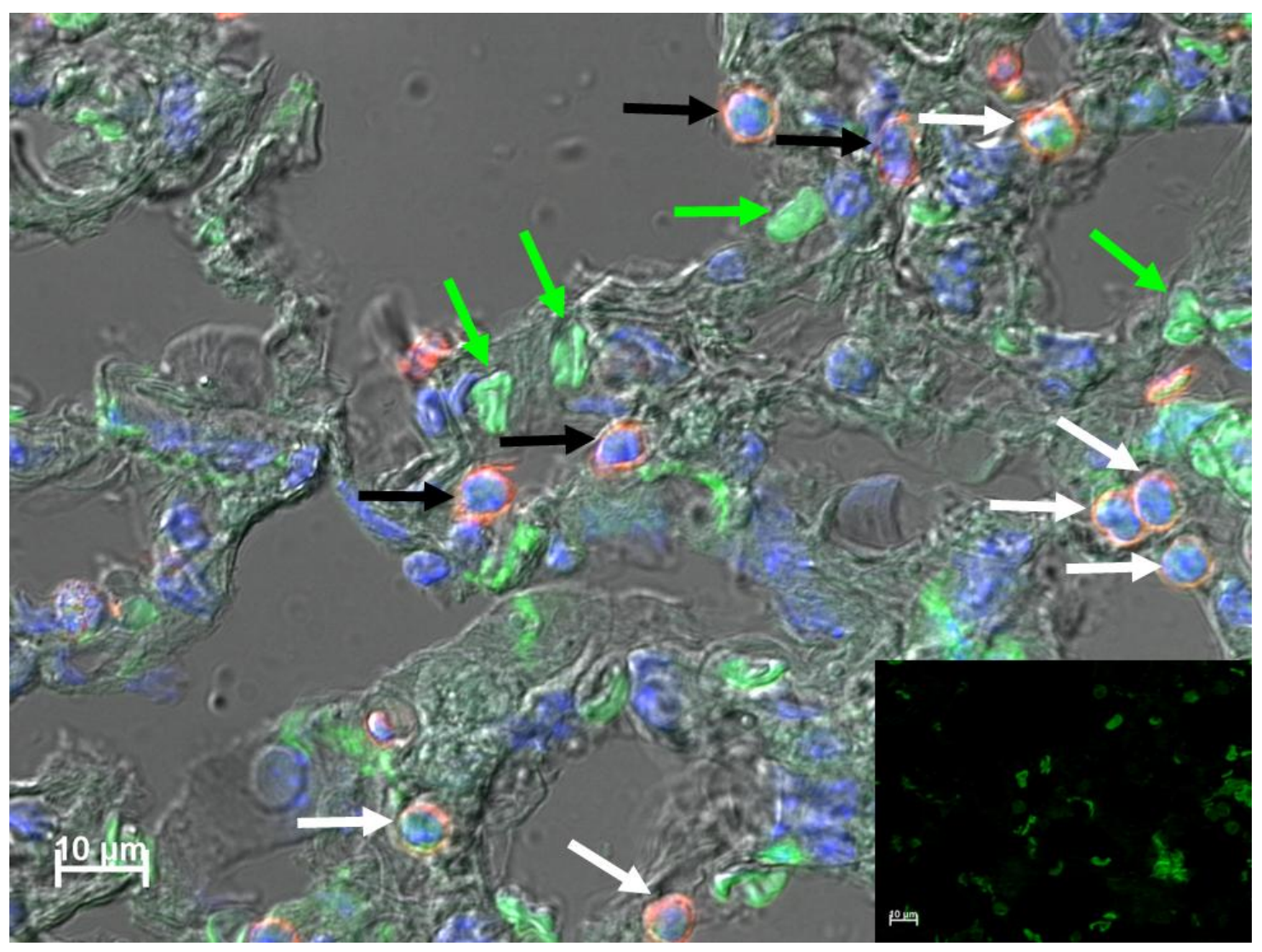

Figure 6

A

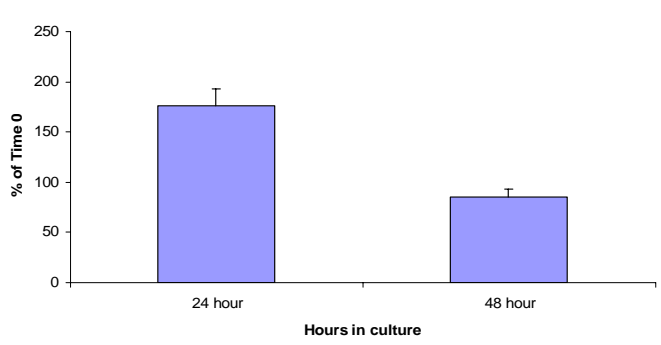

C

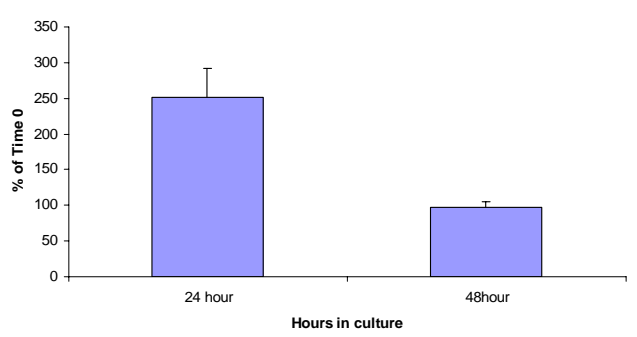

B

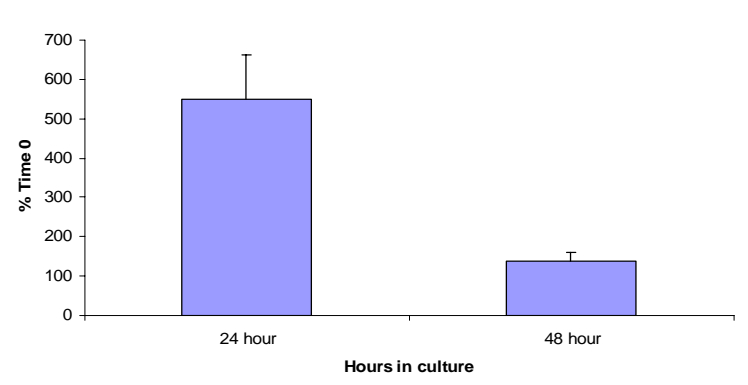


Figure 7

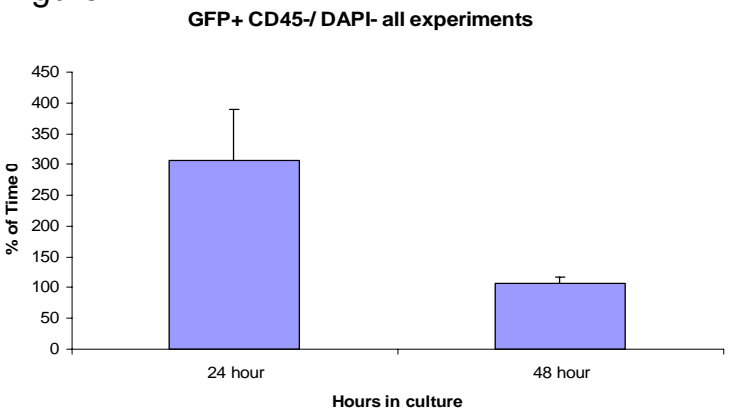

Figure 8

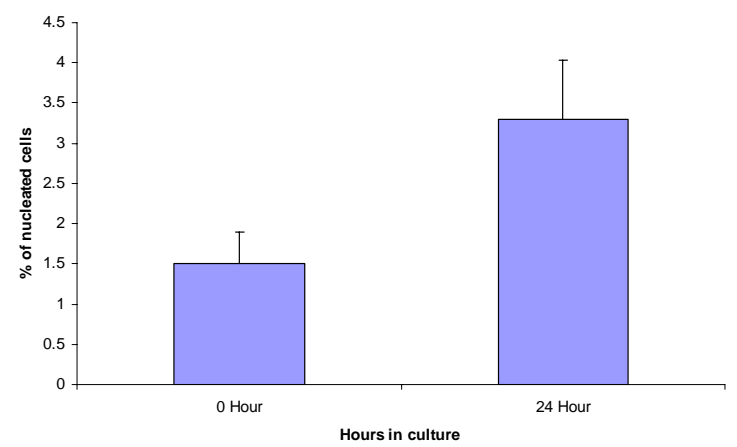

Figure 9

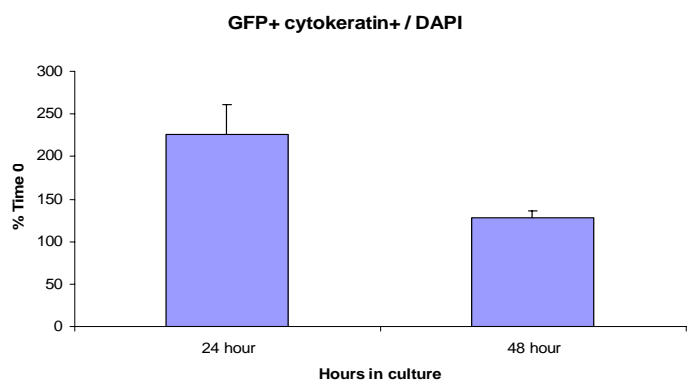


Figure legends:

Figure 1. Homing of Lineage negative Sca-1 positive cells. (A) Cell cycle analysis of Lin ${ }^{-}$ Sca- $1^{+}$cells cultured in IL-3, IL-6, IL-11 and SCF at various time points. Cells were analyzed on a flow cytometer using ModFit LT cell cycle modeling software. (B) Homing of CFSE labeled, Lin Sca- $1^{+}$cells to bone marrow in non irradiated hosts, 3 hours post infusion. Cells were either cultured for 0 (no culture), 18, 24, 40 or 48 hours in IL-3, IL-6, IL-11 and SCF prior to transplant. Analysis was done by flow cytometry for the presence of CFSE positive cells. (C) Homing of CFSE labeled, Lin Sca- $1^{+}$cells to organs in non irradiated hosts, 3 hours post infusion. Cells were pretreated prior to transplant as described in $(A)$ and presented as number of events per high powered field. Analysis was done by frozen sections and CFSE positive cells counted per high powered field. (D) Analysis of homed $\mathrm{Lin}^{-} \mathrm{Sca}-\mathrm{1}^{+}$cells by frozen section presented as a percent of the time 0 control. Cells were pretreated as described in A. All error bars represent the standard deviation. If no error bars is seen, the value represents less than 3 animals.

ANOVA followed by Tukey multiple comparisons were done to compare the mean of \%DAPI in lung at 0,18 and 24 hours. The mean \% DAPI were statistically significantly different at least between two of three time points (ANOVA $p=0.007$ ) and Tukey test shows that a significant difference was observed between 0 and 24 hours $(p<0.05)$.

Figure 2. Homing and persistence of cultured GFP Lin Sca- ${ }^{+}$cells to lung. (A-D) Images are a combination of DAPI (blue), GFP (green) and phase contrast utilizing nomarski optics. (AC), 20x objective (D) and (E) 63X objective. (A) Arrows indicate donor GFP positive Lin $^{-} \mathrm{Sca}-1^{+}$ cells 3 hours post infusion. (B) Arrows indicate slight increase in GFP positive cells 7 days post infusion. (C) Arrows show an even larger increase in the number of GFP positive cells at 14 days post transplant and begin to show groups of positive cells. (D) High magnification of a colony like (circle) formation of GFP cells at 14 weeks post transplant. (E) Three dimensional deconvolution of $D$ showing the close proximity of the positive cells.

Figure 3. True fluorescence distinguished from autofluorescence. Section of lung from an animal transplanted with GFP WBM. (A, B, C and D) Digital images of lung, taken with a Zeiss color digital camera. All pictures are from the same tissue section and same field of view, taken through different filters. (A) DAPI alone. (B) FITC alone. (C) Texas Red alone. (D) FITC/Texas Red double bandpass filter. Each numbered arrow corresponds with the same cell or area for all images. Arrows 1 and 2 show clear examples of autofluorescence since the signal is visible both in the FITC (B) and the Texas Red (C) channels. This false signal is easily distinguished from true fluorescence in $\mathrm{D}$ where it is visible as a bright yellow/orange color. Arrows numbered 3 and 4 show a borderline positive cells when viewed through the FITC channel, which are clearly negative when viewed through the double bandpass filter. Arrows numbered 5 in image $B$ show positive green cells with no positivity in the red channel (C) and a green appearance on the double bandpass filter (D) These are true positives.

Figure 4. Colocalization of GFP and cytokeratin in lung cells. (A) Arrows-cells labeled with DAPI showing the location of three nucleated cells. (B) Same field viewed through a FITC filter. White arrows show 2 GFP positive cells, the cell in the lower right corner is GFP negative (circle). (C) Same field viewed through a Texas Red filter. Arrows indicate a positive cell stained with anti cytokeratin/ rhodamine. (D) Overlay of A and B showing GFP positive cytokeratin positive cell (red arrows). The remaining GFP positive cell (lower left corner) is negative for cytokeratin. (E) 3D deconvolution: Donor GFP cells are green. All nucleated cells are counter stained with DAPI (blue). Cytokeratin positive cells are shown in red. (F) Same series of deconvolution as E but only showing GFP positive cells. (G) Same series of deconvolution as E but only showing cytokeratin positive cells. (H) Indicates colocalization of GFP and cytokeratin. (I) Composite picture of DAPI positive cells and GFP positive cells, showing both nucleated GFP positive and GFP negative cells. (J-M) Deconvolution series in clockwise rotation showing up to 180 degree view of the sample. 
Figure 5. The geographic distribution of GFP+ and GFP+/CD45+ cells in lung tissue from a transplanted mouse. Tissue from a mouse transplanted with 5 million $\mathrm{GFP}^{+}$WBM cells and given 2 cycles of G-CSF separated by administration of cardiotoxin into the anterior tibialis muscle. The mouse was irradiated with 1000 cGy prior to cell infusion and evaluated 2 months after the initial transplant. Phase contrast picture taken with Normarski optics in combination with a fluorescent image taken through DAPI, FITC and Texas Red filters. White arrows show GFP ${ }^{+}$ $\mathrm{CD}^{+} 5^{+}$, Black arrows show GFP $\mathrm{CD}^{-} 5^{+}$and green arrows show $\mathrm{GFP}^{+} \mathrm{CD} 45^{-}$cells. Insert: same image showing only FITC.

Figure 6. GFP+CD45- cells per DAPI cell in mice transplanted with GFP+ marrow. GFP ${ }^{+}$ marrow from male C57BL/6-TgN (ActbEGFP)1osb mice was cultured in IL-3, IL-6, IL-11 and steel factor for 0, 24 or 48 hours was injected into 900-1000 cGy treated wild type C57BL/6 mice. These mice received two 5 day courses of G-CSF and their lungs were evaluated 2 months after cell infusion. Some mice had intramuscular cardiotoxin or intratracheal bleomycin between GCSF courses. These results are pooled with those obtained from mice not subjected to additional cardiotoxin or bleomycin injury. (A) Whole unseparated marrow. Frozen sections of lungs from experimental mice were evaluated for GFP fluorescence and the presence of membrane CD45. GFP ${ }^{+}$CD $45^{-}$cells were considered to be derived from donor marrow. The number of transplanted mice evaluated at 0, 24 and 48 hours was 16, 16 and14, respectively. The 24 hour time point in culture (G1/S interface) was significantly different from time $0(p<0.05)$ and by 48 hours the values were back to baseline. The percent of GFP positive CD45 events per nucleated cell (DAPI) at time 0 was 5.78+/-1.6. (B) Lin'Sca-1+ cells from GFP ${ }^{+}$mice were cultured and evaluated as described above. The 24 hour point was significantly different from the 0 and 48 hour time point $(p<0.05)$. There were 4 mice per time point. The $\% \mathrm{GFP}^{+} \mathrm{CD} 45$ events per nucleated cell (DAPI) at time 0 was $0.98+/-0.3$. (C) Combined WBM and Lin Sca- $1^{+}$results. The 24 hour time point is significantly different from 0 and 48 hours $(p<0.05)$. there were a total of 20 transplanted mice at 0 and 24 hours and 18 at 48 hours. The percent GFP ${ }^{+}$CD 45 events per nucleated cell (DAPI) was 4.96+/-1.4.

*Whole bone marrow - Anova followed by Tukey multiple comparisons compared normalized values at 0,24 and 48 hours and there were significant differences between at least 2 of 3 time points and the Tukey test showed that there were significant differences between 0 and 24 and 24 and 48 hours $(p<0.05)$. there were no significant differences between 0 and 48 hours.

** Lin ${ }^{-S} \mathrm{Sca}-1^{+}$- Anova followed by Tukey multiple comparisons compared normalized values at 0 , 24 and 48 hours and there were significant differences between at least 2 of 3 time points (ANOVA $p=0.002$ ) and the Tukey test showed significant differences between 0 and 24 and 24 and 48 hours $(p<0.05)$. There were no significant differences between 0 and 48 hours.

*** All experiments combined - ANOVA followed by Tukey multiple comparisons compared normalized values at 0,24 and 48 hours and there were significant differences between at least 2 of 3 time points (ANOVA $p=0.002$ ) and the Tukey test showed significant differences between 0 and 24 and 24 and 48 hours $(p<0.05)$. there were no significant differences between 0 and 48 hours.

Figure 7. The $\% \mathrm{GFP}^{+} \mathrm{CD} 45^{-}$lung cells/DAPI when data are calculated on a per experiment (culture) basis and expressed as \% time 0 . A total of 6 separate experiments (58 transplanted mice) were analyzed. The 24 hour time point was significantly different from 0 and 48 hours $(p<0.05)$.

All experiments - ANOVA flowed by Tukey multiple comparisons compared normalized values at 0,24 and 48 hours and there were significant differences between at least 2 of 3 time points (ANOVA $p=0.013$ ) and the Tukey test showed significant differences between 0 and 24 and 24 and 48 hours $(p<0.05)$. There were no significant differences between 0 and 48 hours.

Figure 8. GFP ${ }^{+} C D 45$ events per DAPI positive cell in a simplified irradiated mouse model. WBM cells from GFP ${ }^{+}$mice were cultured in IL-3, IL-6, IL-11 and steel factor for 0 or 24 hours. These cells were infused into $900 \mathrm{cGy}$ irradiated C57BL/6 mice and these mice were then 
sacrificed 6 weeks later and their lungs evaluated for $\mathrm{GFP}^{+} \mathrm{CD} 45^{-}$events. There were 4 transplanted mice per time point. The 24 hour time point was significantly different from the 0 hour time point $(p<0.004)$.

Figure 9 . GFP ${ }^{+}$Cytokeratin positive events per DAPI positive cell in irradiated mice transplanted with $\mathrm{GFP}^{+}$marrow. Same model as described for figure 6 The percent $\mathrm{GFP}^{+}$cytokeratin ${ }^{+}$per DAPI positive cell are presented as percent time 0 . These were from experiments with WBM transplanted mice and there were 6, 8 and 6 transplanted mice at 0,24 , and 48 hours, respectively.

ANOVA followed by Tukey multiple comparisions compared normalized values at 0,24 and 48 hours and the values were significantly different between at least 2 of 3 time points (ANOVA $p=0.002$ ) and the Tukey test showed significant differences between 0 and 24 and 24 and 48 hours $(p<0.05)$. No significant differences were not seen between 0 and 48 hours.

Table I. Donor Marrow Cells in Lung (expressed as a percent of 0 hour control)

A. Individual Transplants

\begin{tabular}{|lllllll||}
\hline Group & 24H GFP+ & 24H GFP+CD45+ & N & 48H GFP+ & 48H GFP+CD45+ & N \\
\hline WBM $^{\mathrm{a}}$ & $129 \pm 12^{*}$ & $116 \pm 13$ & 16 & $96 \pm 9$ & $95 \pm 11$ & 14 \\
LinSca-1 $^{+} \mathrm{b}$ & $183 \pm 20^{* *}$ & $153 \pm 17$ & 4 & $129 \pm 24$ & $125 \pm 24$ & 4 \\
All & $140 \pm 11$ & $123 \pm 11$ & 20 & $103 \pm 9$ & $102 \pm 10$ & 20 \\
\hline \hline
\end{tabular}

B. Separate experiments (Individual cultures)

\begin{tabular}{||lllllll||}
\hline Group & 24H GFP+ & 24H GFP+CD45+ & N & 48H GFP+ & 48H GFP+CD45+ & N \\
\hline \hline All & $155 \pm 21$ & $137 \pm 18$ & $6(20)$ & $110 \pm 13$ & $108 \pm 14$ & $6(20)$ \\
\hline
\end{tabular}

a. WBM=Whole Bone Marrow

b. Lin Sca- $1^{+}=$Lineage negative, Stem cell antigen-1 positive

All combined values for WBM and Lin-Sca-1+

Data calculated as the number of events per nucleated cell (DAPI $\left.{ }^{+}\right)$on lung sections and then normalized to percent of 0 hour. Absolute values for 0 hour (A) for WBM was $22.6 \pm 1.8 \%$ GFP+ and $17 \pm 25 \%$ GFP+ CD45+ per nucleated cell (DAPI+), ,for Lin ${ }^{-S c a}-1^{+} 11 \pm 3 \% \mathrm{GFP}^{+}$and $9.6 \pm 2.5 \% \mathrm{GFP}^{+} \mathrm{CD} 45^{+}$per nucleated cell (DAPI+). When all groups were considered $21+1.9$ GFP $\bar{P}^{+} \%$ and $15.5 \pm 1.8 \mathrm{GFP}^{+} \mathrm{CD} 45^{+} \%$ per nucleated cell were the values at time 0 . The absolute values for time 0 in individual experiments (separate cultures) for Lin Sca- $1^{+}$was $17 \pm 3.5 \% \mathrm{GFP}^{+}$ and $13.7 \pm 2.7 \% \mathrm{GFP}^{+} \mathrm{CD}^{+} 5^{+}$per nucleated cell (DAPI+)

* WBM group - ANOVA followed by Tukey multiple comparisons compared normalized values at 0,24 and 48 hours and there were significant differences between at least 3 of 3 time points (ANOVA $p=0.015$ ) and the Tukey test showed significant differences between 0 and 24 and 24 and 48 hours.

** Lin Sca- $1^{+}$group - ANOVA followed by Tukey multiple comparisons to compare normalized values at 0,24 and 48 hours showed that there were significant differences between at least 2 of 3 time points (ANOVA $p=0.026$ ) and Tukey test showed significant differences between 0 and 24 hours 